\title{
DOES NEOPLASTIC CHOLECYSTOKININ EXPRESSION REFLECT THE EMBRYONAL PATTERN OF THE PROTEIN? A STUDY IN HUMAN PANCREAS
}

\author{
Demetrio Tamiolakis ${ }^{1}$, Ioannis Venizelos ${ }^{2}$, Constantine Simopoulos 3 , Maria Lambropoulou ${ }^{4}$, Athanasia Kotini ${ }^{5}$, \\ Theodoros Jivannakis ${ }^{6}$, George Alexiadis ${ }^{4}$, Panagiotis Boglou ${ }^{4}$, and Nikolas Papadopoulos ${ }^{4}$ \\ General Hospital of Chania, Greece: Department of Cytology ${ }^{1}$; Ippokration Hospital of Salonica, Greece: Department of \\ Pathology2; Democritus University of Thrace, Greece: Department of Experimental Surgery ${ }^{3}$, Department of Histology- \\ Embryology ${ }^{4}$; Department of Medical Physics ${ }^{5}$; General Hospital of Drama, Greece: Department of Pathology ${ }^{6}$
}

\begin{abstract}
Summary: Aim: To determine the immunoreactivity of cholecystokinin (CCK) during the development of the human fetal pancreas and pancreatic adenocarcinoma, given that, CCK positive cells were demonstrated either in its embryonic anlage or in pancreatic cancer. In order to obtain possible parallels in the expression pattern of neoplastic cells in adults (well moderately - poorly differentiated), we investigated the pattern of CCK expression in the pancreatic tissue during the various stages of development and compared these with the proliferation of tissue assessed by proliferating cell nuclear antigen (PCNA) immunohistochemistry. Experimental design: Tissue sections from 15 pancreatic fetal specimens, and equal number of ductal adenocarcinoma specimens, were assessed using immunohistochemical methods for CCK. Results: The density of positive cells in the primitive exocrine ductal walls and outgrowing buds was significantly higher than the relevant density in the neoplastic pancreatic tissue of mixed (ductal - endocrine) and pure ductal type $(\mathrm{p} 1=0.004, \mathrm{p} 2<0.0005$, p $3<0.0005$ and $\mathrm{p} 4=0.023$ respectively). The above values were estimated from $20^{\text {th }}$ to $22^{\text {nd }}$ weeks of gestation. There was no significant difference in the density of positive cells in the islet cell epithelium from 25-30 weeks, and the neoplastic tissue of mixed ( $\mathrm{p} 5=0.10)$ and pure ductal type ( $\mathrm{p} 6=0.15)$. Conclusions: The immunostaining for CCK identifies a subgroup of pancreatic ductal adenocarcinomas with a neuroendocrine component (initially considered as pure ductal tumors), and mixed ductal-endocrine tumors. This pattern of expression in neoplasms recapitulates the normal pattern during the embryonal development of the organ, and may be important for the development of new therapeutic approaches with eventual clinical utility.
\end{abstract}

Key words: Cholecystokinin; Fetal pancreatic tissue; Pancreatic carcinoma

\section{Introduction}

The cholecystokinin (CCK) is a gastrointestinal polypeptide hormone, closely related chemically to gastrin. It was supposed primarily to be implicated in the control of pancreatic and biliary secretion, gall-bladder contraction, and gut motility $(5,25,17,26)$, but recent studies have pointed out a key role of it in the central nervous system as well, perhaps as a neurotransmitter or neurohormone $(3,4,5$, 25,29). The peripheral actions of CCK are mediated by a receptor subtype termed as CCK-A, while the central actions are mediated by a receptor subtype termed as CCK-B, for which the minimum agonist ligand required is CCK-4, i.e., Try-Met-Asp-Rhe- $\mathrm{NH}_{2}$, (33), which is identical to tetragastrin (G-4). A third receptor subtype, which appears to be closely related to CCK-B subtype, is the stomach gastrin receptor (1).
Pancreatic carcinoma remains one of the most devastating neoplasms of the gastrointestinal tract. Pancreatic cancer is a malignancy that is unresponsive to conventional therapy. More than $85 \%$ of patients have metastatic disease when they are first seen. The incidence of pancreatic cancer is 9 per 100.000 and has remained steady since 1973 (23). Median survival on diagnosis is 11 months, whereas adjuvant treatment (5-fluorouracil and radiation treatment) with surgical resection (Whipple procedure) has extended life by approximately 9 months (16). A dismal prognosis is associated with pancreatic adenocarcinoma despite multimodality treatment protocols. Although total pancreatectomy in selected patients offers survival advantages in rare cases, the difference remains negligible (32). Earlier diagnosis and novel treatment modalities may help to improve survival in patients with pancreatic cancer. 
One day the dismal prognosis of this disease may be improved by a better understanding of its pathogenesis. Neoplasms of the pancreas arise from ductal, acinar, stromal, or islet cells. The term carcinoma of the pancreas is customarily used only in reference to exocrine tumors and rare mixed endocrine - exocrine carcinomas. Neoplasms including carcinomas composed primarily of endocrine cells, are collectively termed islet cell tumors. The precursors of these tumors are presumably developmentally multipotent in terms of their capacity to differentiate into various cell types producing various hormones and regulatory peptides. Whether these cells originate from the ductular epithelium or the islet cells is a matter of debate (18).

Previous reports examining the type and distribution of CCK receptors in animal pancreas have yielded results which may not be directly applicable to humans. CCK-A receptors have been observed on both normal and neoplastic rat pancreas $(10,27)$. In some cases of rat pancreatic adenocarcinoma, these receptors are overexpressed (34). Furthermore, in some nonhuman pancreatic cancer models, expression of CCK-B receptors has been identified on malignant tissue but not on normal pancreas (34). The relationship between different animal models of pancreatic cancer and humans remains controversial $(10,20)$. The majority of human pancreatic adenocarcinomas appear to be of ductal cell origin, while pancreatic malignancy in most animal models arises in acinar cells. While it is possible that among different species there is significant variation in the cell of origin for pancreatic adenocarcinoma, there is also substantial evidence to support the possibility of a pancreatic stem cell capable of differentiation into ductal or acinar cell types (15). Furthermore, transdifferentiation from acinar to ductal cell phenotype has been described as a potential link between exocrine pancreatic cell types $(9,10)$. Thus, pancreatic tumor development in animals and humans could originate in the same cell type, with variable subsequent differentiation.

This study demonstrated and compared the CCK expression in human fetal pancreas from 20-22 and 25-30 weeks of development, and pancreatic adenocarcinoma. We attempted to track the normal expression fashion of $\mathrm{CCK}$ in tissues with different proliferative and differentiating regions and to search whether CCK expression in pancreatic cancer simulates the normal model of display, or may result from neoplastic disarray. We conclude that the efficacy of CCK administration in pancreatic cancer is yet to be determined.

\section{Materials and methods}

\section{Tissue Sampling}

The pancreatic tissues were obtained by pancreatoduodenectomy (The Whipple procedure) for carcinoma of the pancreas. Samples from the pancreas of 15 consecutive surgical patients (eight males and seven females, aged from 48 to 74 years, average $57.8 \pm 11.2$ ) were included in the stu- dy. Two tissue samples were taken from each patient: one from the tumor and one from the resection margin to serve as a negative control. All tumors were verified as pancreatic adenocarcinomas with various degrees of differentiation. The carcinomas were graded according to their cytologic appearance as well differentiated (grade 1, 5 cases), moderately differentiated (grade 2, 8 cases), and poorly differentiated (grade 3, 2 cases).

In order to obtain possible parallels in the expression pattern of neoplastic cells in adults (well - moderately poorly differentiated), we investigated the pattern of CCK expression in the pancreatic tissue during the various stages of development and compared these with the proliferation of tissue assessed by proliferating cell nuclear antigen (PCNA) immunohistochemistry. The tissues from the resection margins likewise were examined histologically and were found to be free of tumor cells.

Human embryonic (fetal) pancreatic tissue from fifteen fetuses after involuntary abortion (20 to 22 gestational weeks 8 samples: 3 cases due to infectious factors, 2 cases to endocrine factors, and 3 cases to placental abnormalities. 25 to 30 weeks 7 samples: 5 cases due to leiomyoma, and 2 cases to endometriosis - adenomyosis), was investigated.

The local hospital ethics committee approved the use of human tissue, and written informed consent was obtained from all patients.

\section{Immunohistochemical procedure}

Cholecystokinin (CCK) immunoreactivity was evaluated using the lyophilised Polyclonal (NCL-CCK-8p) on formalin-fixed, paraffin-embedded samples. Serial sections of the tissue were cut into 3-m thick slices and immunohistochemistry was performed by the avidin-biotin complex (ABC) method, using NOVOCASTRA kits. Briefly, after the sections had been dewaxed and rehydrated, they were washed in phosphate-buffered saline (PBS) and incubated for $30 \mathrm{~min}$ in normal goat serum to inhibit nonspecific binding. The sections were then washed in PBS and incubated with antibody against CCK (NCL-CCK-8p) overnight at $4{ }^{\circ} \mathrm{C}$. The primary antibody was used after dilution $(1: 150)$.

CCK (NCL-CCK-8p) immunoreactivity was cytoplasmic, with only occasional and faint nuclear immunostaining. For each sample positive cells in the ducts, islets of Langerhans, aggregates or isolated cells in the pancreatic parenchyma, ware assessed by enumeration of labeled cells in each tissue compartment for a minimum of five random fields per section viewed at 40-fold magnification through a grid. Cell number was calculated per $1 \mathrm{~mm}^{2}$ of tissue section. The counted areas were selected from random fetal and neoplastic pancreatic tissue sections, taking into account that the ratio of the exocrine pancreatic area (acinoracemose), according to the endocrine pancreatic area (islets of Langerhans) was entirely representative. Statistical analysis was obtained using the t-test. 


\section{Results}

\section{Embryonal pancreatic tissue}

20 - to 22 - week - old human embryos: During this period of development, enteroendocrine cells demonstrated a strong positive immunoreactivity for CCK (NCL-CCK-8p), initially in the primitive exocrine duct epithelium amongst the undifferentiated columnar ductal cells (density of CCK positive cells $=$ mean of cells $/ \mathrm{mm}^{2}$ of tissue $\mathrm{SEM}=$ $37.1 \pm 1.5$ ) (Fig. 1) or forming small aggregates (buds) in the surrounding the ductal structures, loose mesenchymal tissue (density of CCK positive cells $=$ mean of cells $/ \mathrm{mm}^{2}$ of tissue $\pm \mathrm{SEM}=21.6 \pm 0.8$ ) (Fig. 2).

From the $25^{\text {th }}$ to the $30^{\text {th }}$ week of gestation, a strong positive immunostaining for CCK (NCL-CCK-8p) was observed to APUD cells of the islet cortex epithelium (density of CCK positive cells $=$ mean of cells $/ \mathrm{mm}^{2}$ of tissue \pm SEM $=28.1 \pm 1.3$ ). Expression of CCK in the pancreatic tissue from pregnancies up to $20-30$ weeks varied considerably

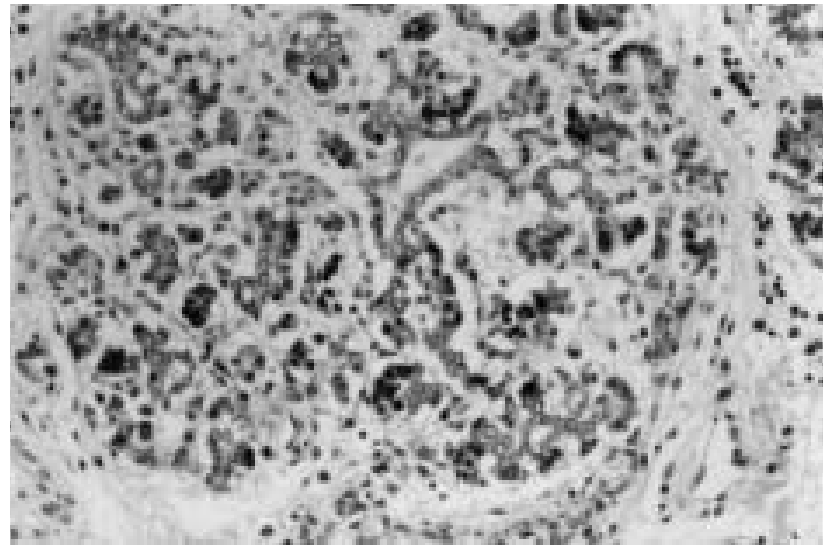

Fig. 1: CCK expression in the primitive exocrine ductal epithelium. NCL-CCK-8p X100.

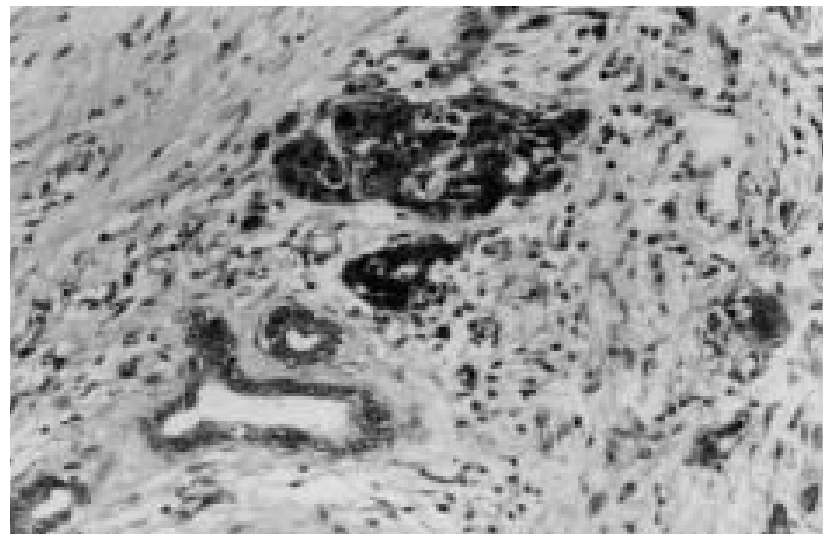

Fig. 3: CCK expression in neoplastic pancreatic tissue with recapitulation of the relevant expression of the antigen in the primitive embryonal pancreatic anlage. NCL-CCK8 p X200. both within and among specimens and no-age specific pattern could be detected. Neither did cells in any location (walls - buds - cortex) showed any particularly strong difference in staining intensity.

\section{Neoplastic pancreatic tissue}

CCK was demonstrated in ten out of fifteen pancreatic adenocarcinomas. The five CCK negative pancreatic adenocarcinomas were of mucinous type. CCK positive cells constituted the majority of neoplastic cells in the ductlike structures or small cords of the tumor. Especially, in six cases diagnosed as mixed ductal - endocrine carcinoma, the density of CCK positive cells was $30.4 \pm 1.2$ cells $/ \mathrm{mm}^{2}$ (Fig. 3); in the remaining four cases diagnosed as typical ductal adenocarcinoma the density of CCK positive cells was $25.4 \pm 1.6$ cells $/ \mathrm{mm}^{2}$ (Fig 4).

There was a statistically significant difference in the expression of CCK in the ductlike structures of the primitive exocrine embryonal pancreatic tissue from the $20^{\text {th }}$ to

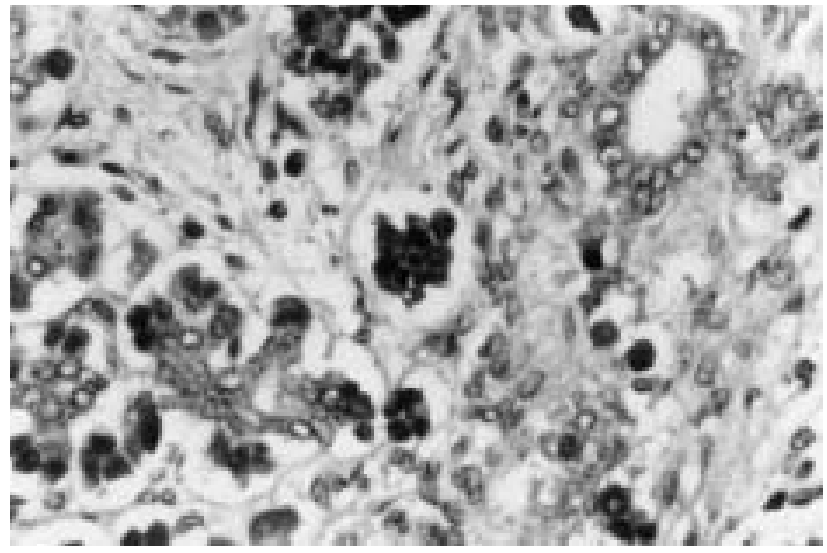

Fig. 2: CCK expression in the primitive exocrine ductal buds. NCL-CCK-8p X200.

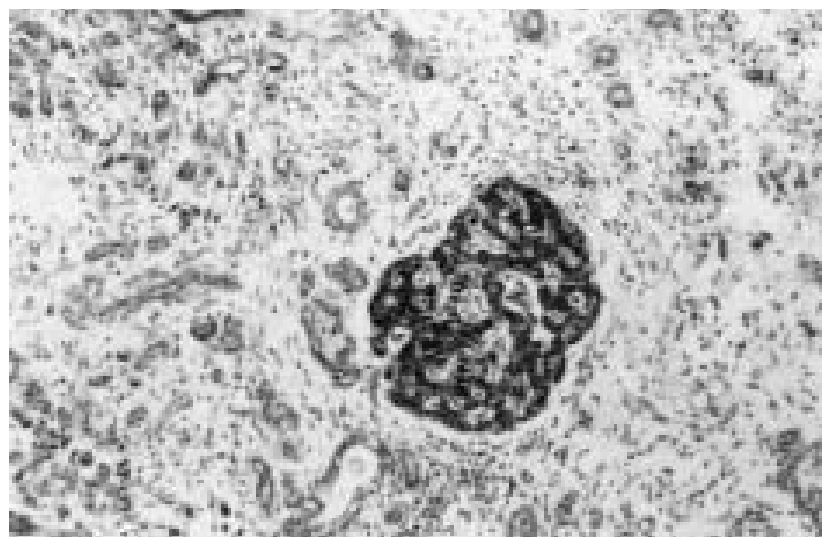

Fig. 4: CCK expression in pancreatic adenocarcinoma of pure ductal type NCL-CCK-8p X100. 
Tab. 1: Reactivity of CCK (NCL-CCK-8p) in human embryonal and neoplastic pancreatic tissue.

\begin{tabular}{|l|c|c|}
\hline Pancreatic tissue & Number of cases & $\begin{array}{c}\text { Density of CCK positive cells } \\
\text { (average cells/mm }{ }^{2} \text { of tissue } \pm \text { SEM) }\end{array}$ \\
\hline Embryonal (20-22 weeks) & 8 & $37.1 \pm 1.5$ \\
Primitive exocrine duct walls & & $21.6 \pm 0.8$ \\
Primitive exocrine ductal buds & & \\
\hline Embryonal (25-30 weeks) & 7 & $28.1 \pm 1.3$ \\
Islet cortex epithelium & 10 & $30.4 \pm 1.2$ \\
\hline Neoplastic tissue & 6 & $25.4 \pm 1.6$ \\
Mixed ductal-endocrine carcinoma & 4 & \\
Pure ductal carcinoma & & \\
\hline
\end{tabular}

the $22^{\text {th }}$ gestational week, over the neoplastic pancreatic tissue of mixed type $(\mathrm{p} 1=0.004)$ and pure ductal type $(\mathrm{p} 2<0.0005)$.

There was also a statistically significant difference in the expression of CCK in the buds surrounding the ductal structures of the primitive exocrine embryonal pancreas from the $20^{\text {th }}$ to $22^{\text {th }}$ over the neoplastic pancreatic tissue of mixed type $(\mathrm{p} 3<0.0005)$ and pure ductal type $(\mathrm{p} 4=0.023)$.

No statistically significant difference was observed in the expression of CCK in the islet cortex tissue from the $25^{\text {th }}$ to the $30^{\text {th }}$ week, in comparison with the neoplastic tissue of mixed type $(\mathrm{p} 5=0.10)$ and pure ductal type (p6=0.15).

The density of PCNA positive cells was $0-4 \pm 1.2$ cells $/ \mathrm{mm}^{2}$ in the primitive exocrine ductal walls; $0-7 \pm 1.2$ cells $/ \mathrm{mm}^{2}$ in the primitive exocrine ductal buds; $0-6 \pm 1.3$ cells $/ \mathrm{mm}^{2}$ in the islet cortex epithelium; $26.6 \pm 1.3$ cells $/ \mathrm{mm}^{2}$ in the mixed ductal endocrine carcinoma and 32.1 \pm 1.7 cells $/ \mathrm{mm}^{2}$ in the pure ductal carcinoma. So PCNA and CCK immunoreactivity showed a clear inverse relationship in the two types of carcinoma. On the contrary, a negative relationship was found between the two antigens during the embryonic pancreatic tissue development.

\section{Discussion}

CCK, a peptide hormone produced in the upper small intestine, is known to stimulate the secretion and growth of the normal exocrine pancreas (28). Many studies have been conducted to examine the role of CCK in the development of pancreatic adenocarcinoma and promotion of its growth once established.

There is considerable evidence supporting a central role for cholecystokinin (CCK) in human pancreatic cancer (11). The influence of endogenous hormones is well-described for several human malignancies, including breast, ovary, and prostate. Generally, the hormones implicated are important in both the health and disease of their target organ. CCK is an important mediator in the growth of the normal pancreas $(21,27)$. Animal studies in which exogenous CCK was administered or in which endogenous CCK levels were manipulated documented pancreatic hyperplasia, dysplasia, and the production of frank malignancies
(8). Similar studies after the induction of pancreatic tumors suggest that CCK administration accelerates the growth of malignant tissue compared to uninvolved tissue $(6,13)$. In human cancer cell lines and xenografted human tumors, CCK promotes the growth of pancreatic adenocarcinoma $(14,31)$. The identification of a specific molecular marker for pancreatic cancer could be of substantial diagnostic and therapeutic benefit.

The role of CCK-A or -B receptors in human pancreatic carcinogenesis remains unclear. The growth of several human neoplastic cell lines derived from pancreas (31), colon (12), and lung (22) is stimulated by CCK or gastrin in vitro. Functional CCK-B receptors have been demonstrated on human biopsy specimens of small cell lung (22) and colon cancers (12), implicating a potential role for CCK or gastrin in human carcinogenesis (30). The demonstration of novel CCK-A receptor expression specifically on ductal cells in pancreatic adenocarcinomas is intriguing. This unique expression could reflect the presumed ductal origin of human pancreatic tumors. CCK-A receptors may be expressed at very low levels in ductal cells in normal human pancreas, below the level of detection by current techniques (24). Tumorigenesis may expand the population of ductal cells, increasing the expression of CCK-A receptors. In addition, CCK-A receptors on ductal cells may play a direct role in mediating the process of pancreatic tumorigenesis.

Alternatively, these studies are consistent with the hypothesis that CCK-A receptors may be a feature only of the developing human pancreas. CCK-A receptors might predominate during human fetal pancreatic development, but their expression would be unnecessary in normal adult pancreas. It has been suggested that CCK mediates normal pancreatic growth and development (27). Previous studies in the calf have demonstrated the expression of CCK-A receptors during fetal development, but with a predominance of CCK-B receptors in the normal adult bovine pancreas (19). Expression of novel antigens by pancreatic neoplastic cells, including fetal markers, has been described (7). Accordingly, expression of CCK-A receptors in pancreatic adenocarcinomas may reflect the reexpression of fetal markers during tumorigenesis. The expression of CCK-A receptors by human fetal pancreas is currently under examination in this laboratory. 
Although there is a substantial body of literature supporting a role for CCK in the modulation of pancreatic cancer growth, our unpublished preliminary data do not support this hypothesis.

The aim of our paper pointed towards the CCK expression in embryonic and neoplastic pancreata. In the embryo, CCK was expressed in distinguished growth steps implying a differentiation - related role. Our data reveal the behavioral potentialities of the glandular epithelium in the neoplastic pancreas as well, thus indicating that the human epithelial cells in the branching ducts of the neoplastic pancreas employ progenitor cells, which if properly triggered differentiate into endocrine cells such as the cells expressing CCK.

The incidence of cancer is increased either by the influence of a carcinogen with a direct impact on DNA or by an increase in cell proliferation (2). The increased cell proliferation may also be related to the decreased cell proliferation. Therefore, the decrease of CCK may indicate cellular dedifferentiation. Results from our examination of carcinomas, revealed low CCK expression in less-differentiated tissues with a high cell turnover.

In conclusion, CCK immunoreactivity appears to show a negative correlation with cell proliferation and differentiation in these developing, normal adult and pathologically transformed adult pancreatic tissues. Within more heterogeneous groups such as mixed carcinomas, further studies will be needed to determine whether there are criteria that may help in estimating the potential for malignancy in the altered tissues.

\section{References}

1. Beinfeld MC. Cholecystokinin in the central nervous system: a minireview. Neuropeptides 1983;3(6):411-27.

2. Cohen SM, Ellwein LB. Cell proliferation in carcinogenesis. Science 1990;249:1007-11.

3. Dockray GJ. Immunochemical evidence of cholecystokinin-like peptides in brain Nature 1976;264(5586):568-70.

4. Dockray GJ, Gregory RA, Hutchison RA, Harris JB, Runswick MJ. Isolation, structure and biological activity of two cholecystokinin octapeptides from sheep brain. Nature 1978;274(5672):711-3.

5. Dockray GJ. The physiology of cholecystokinin in brain and gut. Br Med Bull 1982;38(3):253-8

6. Douglas BR, Wouterson RA, Jansen JB, DeJong AJ. Influence of cholecystokinin and bombesin on azaserine induced lesions in the rat pancreas. Gastroenterology 1989;96:462-9.

7. Escribano MJ, Cordier J, Nap M, Ten F, Kate, Burtin P. Differentiation antigen in fetal human pancreas. Re-expression in cancer. Int J Cancer 1986:38:155-60.

8. Folsch UR, Winckler K, Wormsley KG. Influence of repeated administration of cholecystokinin and secretin on the pancreas of the rat. Scand J Gastroenterol 1978;13:663-71

9. Hall PA, Lemoine NR. Rapid acinar to ductal transdifferentiation in cultured human exocrine pancreas. J Pathol 1992;166:97-103.

10. Hall PA, Lemoine NR. Models of pancreatic cancer. Cancer Surv 1993 16:135-55.

11. Herrington MK, Adrian TE. On the role of cholecystokinin in pancreatic cancer Int J Pancreatol 1995;17:121-38.

12. Hoosein NM, Keiner PA, Curry RC, Brattain MG. Evidence for autocrine growth stimulation of cultured colon tumor cells by a gastrin/cholecystokinin-like peptide. Exp Cell Res 1990;186: 15-21.
13. Howatson AG, Carter DC. Pancreatic carcinogenesis enhancement by cholecystokinin in the hamster nitrosamine model. Br J Cancer 1985;51:107-14.

14. Hudd C, LaRegina MC, Devine. Response to exogenous cholecystokinin of six human gastrointestinal cancers xenografted in nude mice. Am J Surg 1989; 157:386-94.

15. Iovanna JL, de la Porte PL, Dagorn JC. Expression of genes associated with dedifferentiation and cell proliferation during pancreatic regeneration following acute pancreatitis. Pancreas 1992;7:712-8.

16. Kalser MH, Ellenberg SS. Pancreatic cancer. Adjuvant combined radiation and chemotherapy following curative resection. Arch Surg 1985;120:899-903.

17. Kersterns PJ, Lamers CB, Jansen JB, de Jong AJ, Hessels M, Hafkensheid JC. Physiological plasma concentrations of cholecystokinin stimulate pancreatic enzyme secretion and gallbladder contraction in man. Life Sci 1985;36(6): $565-9$.

18. Kloppel G, Heitz PU. Pancreatic endocrine tumors. Pathol Res Pract 1988;183: $155-68$.

19. Le Meuth, V, Philouze-Rome V, et al. Differential expression of the A- and B-subtypes of the cholecystokinin/gastrin receptors in the developing calf pancreas. Endocrinology 1993:133: 1182-91.

20. Logsdon CD. Pancreatic duct cell cultures: there is more to ducts than salty water. Gastroenterology 1995;109:1005-9.

21. Mainz DL, Black O, Webster PD. Hormonal control of pancreatic growth. J Clin Invest 1973; 52:2300-4

22. Matsumori Y, Katakami N, Ito M, Taniguchi T, Iwata N, Takaishi T. Cholecystokinin-B/gastrin receptor: a novel molecular probe for human small cell lung cancer. Cancer Res 1995; 55:276-9.

23. Miller BA, Ries LAG, Hankey BF, Kosary CL, Edwards BK. Cancer Statistic Review: 1973-1989. National Cancer Institute. NIH Publication 1992;92. 2789

24. Monstein HJ, Nylander AG, Salehi A, Chen D, Lundquist I, Hakanson R. Cholecystokinin-A and cholecystokinin-B/gastrin receptor mRNA expression in the gastrointestinal tract and pancreas of the rat and man. Scand J Gastroenterol 1996;31:383-90.

25. Morley JE. Minireview. The ascent of chelecystokinin (CCK)-from gut to brain Life Sci 1982;30(6):479-93.

26. Mutt V. Chemistry, isolation and purification of gastrointestinal hormones. In: Gastrointestinal Hormones. Glass, G.B.J.;Ed.; Raven Press: New York, 1980: pp.169.

27. Povoski SP, Zhou W, Longnecker DS, Bell R. Cholecystokinin receptor characterization and cholecystokinin-A receptor mRNA expression in transgenic mouse pancreatic carcinomas and dysplastic pancreas. Oncol Res 1994;6:411-7.

28. Povoski SP, Zhou W, Longnecker DS, Jensen RT, Mantey SA, Bell RH. Stimulation of in vivo pancreatic growth in the rat is mediated specifically by way of cholecystokinin A receptors. Gastroenterology 1994;107:1135-46.

29. Rehfeld JF. Neuronal cholecystokinin: one or multiple transmitters? Neurochem 1985;44(1): $1-10$

30. Rehfeld JF, van Solinge WW. The tumor biology of gastrin and cholecystokinin. Adv Cancer Res 1994;63:295-347.

31. Smith JP, Framer ST, Solomon TE. CCK stimulates the growth of six human pancreatic cancer cell lines in serum free medium. Regul Pep 1991;32:341-9.

32. Steele GD, Osteen RT, Winchester DP, Menck HR, Murphy GP. National Cancer Data Base Annual Review of Patient Care. American Cancer Society Publication 54, 1994.

33. Steigerwalt RW, Williams JA. Binding specificity of the mouse cerebral cortex receptor for small cholecystokinin peptides. Regul Pept 1984;8(1):51-9.

34. Zhou W, Povoski S, Bell RH. Overexpression of messenger RNA for the cholecystokinin-A receptor and novel expression of messenger RNA for gastrin (cholecystokinin-B) receptor in azaserine induced rat pancreatic carcinoma. Carcinogenesis 1993; 14:2189-92.

Submitted January 2004.

Accepted February 2004.

Nikolaos Papadopoulos,

Assoc. Professor in Histology-Embryology,

Democritus University of Thrace, Dragana, 68100 Alexandroupolis,

Greece.

e-mail: npapad@med.duth.gr 